\title{
Atrial fibrillation following electric shock requiring cardioversion
}

\author{
Navaraj Paudel, ${ }^{1}$ V.M. Alurkar, ${ }^{1}$ Ramchandra Kafle, ${ }^{1}$ Subash Sapkota ${ }^{2}$ \\ ${ }^{1}$ Department of Cardiology, Manipal College of Medical Sciences, Pokhara, Nepal \\ ${ }^{2}$ Department of Internal Medicine, Manipal College of Medical Sciences, Pokhara, Nepal. \\ Corresponding author, Navaraj Paudel \\ Department of cardiology, Manipal College of Medical Sciences, Pokhara, Nepal, Email: drnavarajmd@gmail.com
}

\begin{abstract}
Cardiac arrhythmias following electrical injury falls in a minority. Atrial arrhythmias including atrial fibrillation secondary to electrical shock are even more uncommon. This is a case report of AF requiring pharmacological cardioversion on a 41 year old female following an electrical shock. Initial attempt of electrical cardioversion had failed. Successful pharmacological cardioversion was achieved after 6 hours of amiodarone infusion (12-13 hours after the electric shock). Baseline electrocardiography showed normal pattern post cardioversion. Serum cardiac specific markers, electrolytes, thyroid function, chest $\mathrm{x}$-ray and echocardiographic reports were all within normal limits.
\end{abstract}

Key words: Electrical shock, Atrial fibrillation, Cardioversion.

\section{Introduction:}

Cardiac arrhythmia following electrical injury is uncommon. Most arrhythmias following electric shock include premature ventricular contractions, ventricular tachycardia, ventricular fibrillation, atrial tachycardia, atrial fibrillation, bundle branch block, and complete heart block. ${ }^{1,2}$ These arrhythmias are more common with alternating current $(\mathrm{AC})$ with higher voltage. $\mathrm{AF}$ after electrical shock is uncommon and that too requiring cardioversion is rare. In a study of 182 cases of electrical shock, two had AF and only one required cardioversion. ${ }^{3}$ This is a case report of AF following elec tric shock which did not revert spontaneously and required cardioversion.

A 41 years old female presented to emergency department with the complain of palpitations and
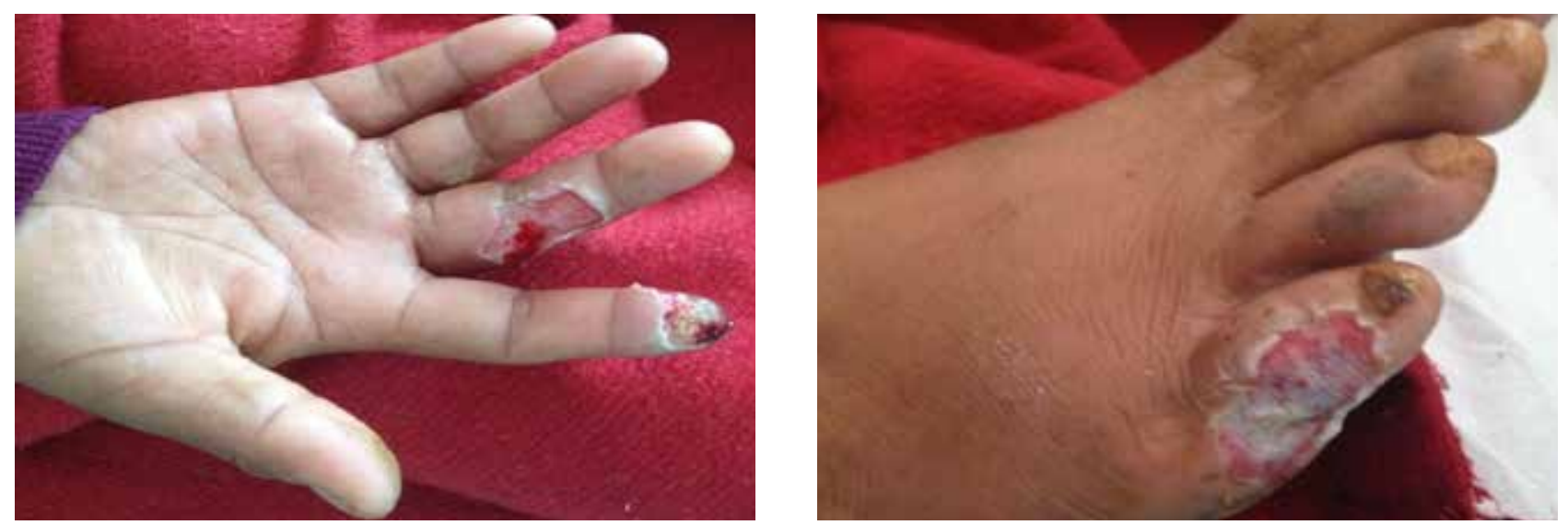

progressive shortness of breath 6 hours after an electric shock from an alternating current source. It occurred when she accidentally came into contact with a live wire of an electrical appliance with her wet hands. She was giddy but did not lose consciousness. She sustained burn over her fingers and toe. She had no significant history in past suggestive of cardiac illness. Physical examination revealed heart rate of $160 / \mathrm{min}$; irregularly irregular with pulse deficit of 40/min. Blood Pressure was 90/60 $\mathrm{mmHg}$. Bilateral fine basal crepitations were present on chest auscultation. Other systemic examination was normal. Local examination revealed two entry wounds on the ventral aspect of tip of index finger and medial aspect of middle finger of right hand and the exit wound present in the lateral part of small toe of right lower limb

Figure 1: Entry and exit wounds. 


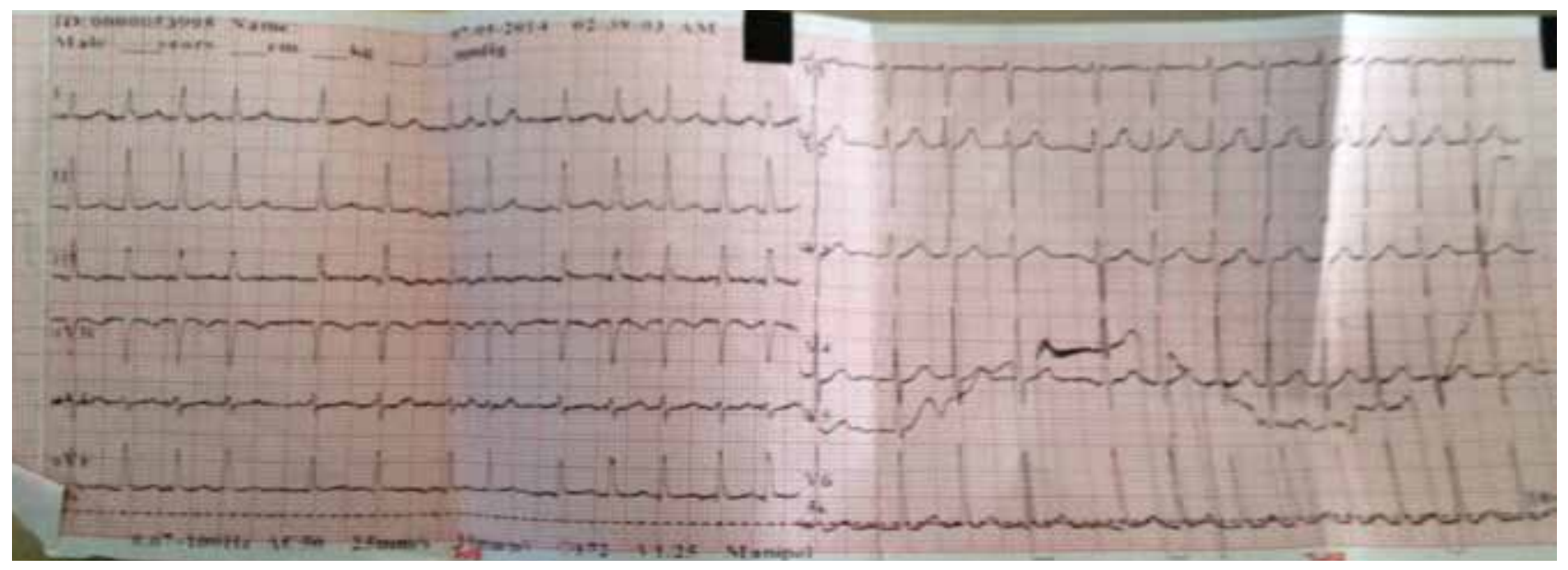

Figure 2: ECG showed AF with rapid ventricular response.

She was given IV metoprolol tartarate $5 \mathrm{mg}$ slowly over few minutes but failed to convert the rhythm to sinus, rather the BP dropped to $80 / 50 \mathrm{mmHg}$. An emergency echocardiography was performed. Injection Heparin 5000 units IV bolus was given. She was then continued with Low Molecular Weight Heparin $60 \mathrm{mg}$ $\mathrm{s} / \mathrm{c}$ twice a day. DC Electric cardioversion was attempted using biphasic defibrillator thrice at the strength of 100J, 200J, 200J respectively but failed to revert the rhythm to sinus. She was then transferred to Coronary Care Unit for medical cardioversion and started on amiodarone $150 \mathrm{mg} \mathrm{IV}$ bolus followed by $1 \mathrm{mg} / \mathrm{min}$ IV infusion for 6 hours and $0.5 \mathrm{mg} / \mathrm{min}$ IV infusion over next 18 hours according to standard protocol. Approximately around 6 hours of IV infusion about 12 to13 hrs post electric shock she reverted to normal sinus rhythm and maintained thereafter.

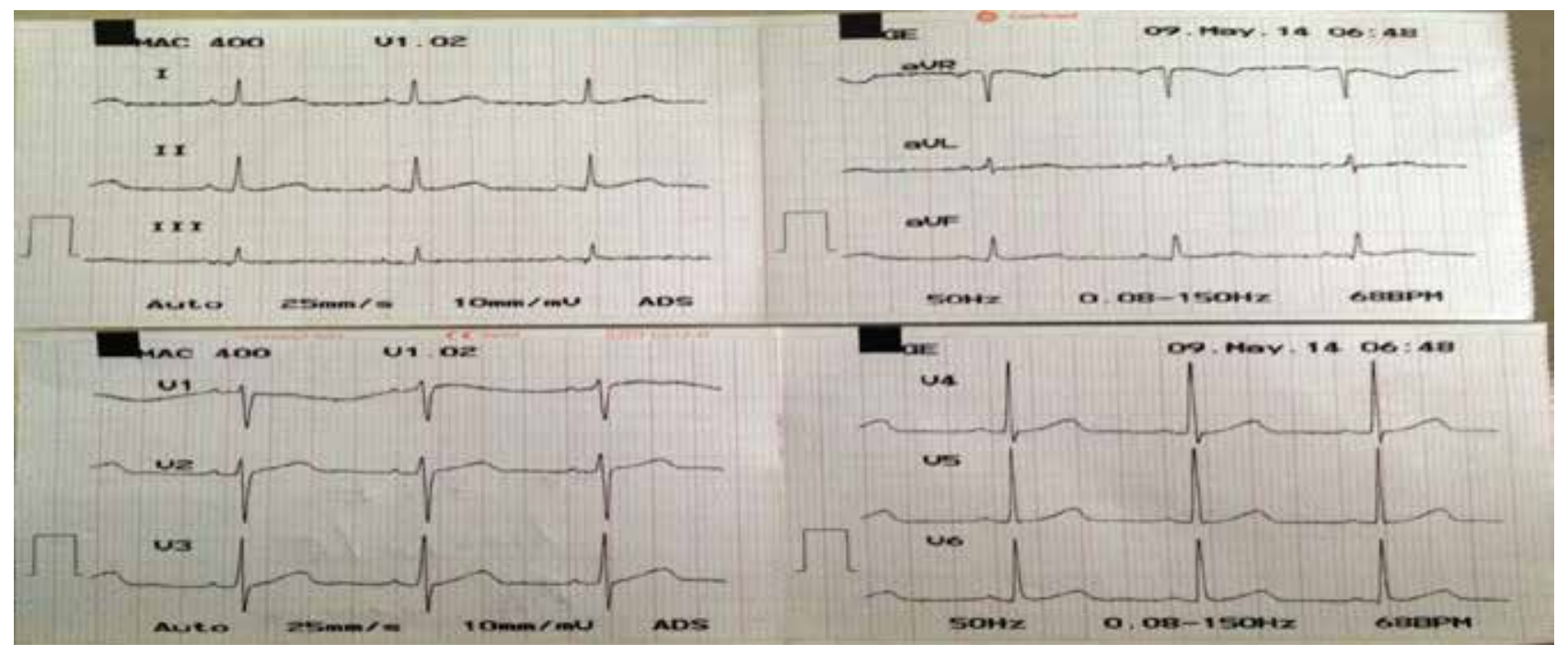

Figure 3: ECG after cardioversion showed normal sinus rhythm 


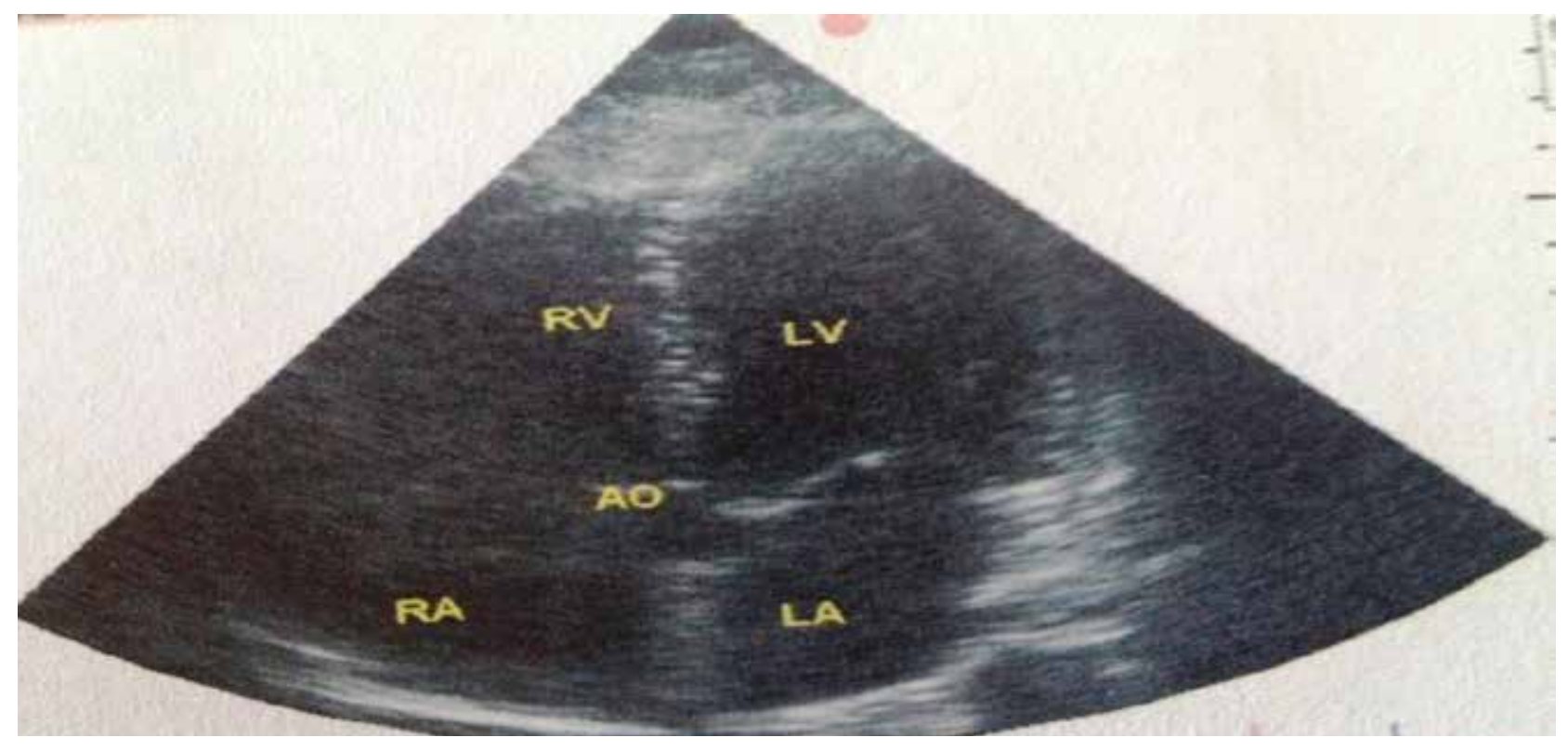

Figure 4: 2D Echocardiogram (Five chamber view)

She was discharged on the fourth day after surgical review for wound care and continued with oral aspirin $75 \mathrm{mg}$ once daily and amiodarone $100 \mathrm{mg}$ twice daily. She was followed up 2 weeks later, free of complaints and the 12 lead ECG was normal.

\section{Discussion:}

Around 5000 patients present to emergency department yearly following electrical injury. It represents $2 \%$ to $7 \%$ of all admissions to burn units in the US with approximately $1 / 5$ th deaths annually. ${ }^{4}$ Currently no data is available regarding electrical injuries in Nepal.

Electrical injury has multisystem effect including skin, respiratory, cardiac, neurological and renal. The incidence of cardiac arrest after electrical injury ranges from $4 \%$ to $17 \%$, as evidenced by numerous studies. ${ }^{5}$ Among those, the most devastating presentation following an electrical injury is cardiac arrest. It is suggested that ventricular fibrillation is more common with low-voltage $\mathrm{AC}$ injuries, whereas asystole is seen more often with high-voltage DC injuries. ${ }^{6}$ Other electrocardiogram (ECG) abnormalities reported include sinus tachycardia, right bundle branch block, first-degree AV block, non-specific ST-segment changes, QTc prolongation, premature ventricular contractions and ventricular tachycardia. ${ }^{7,8}$ The mechanism behind electrically induced cardiac arrest is not entirely clear but patchy areas of myocardial necrosis that serve as arrhythmogenic foci, as well as increased cardiac sodium-potassium pump activity is postulated. ${ }^{9}$

$\mathrm{AF}$ which is among the rare complications of electrical injury has also been documented in some case reports..$^{10,11}$ Arrowsmith et al evaluated 145 patients who suffered electrical injury in a centre over a five year period; cardiac arrest was seen only in $3 \%$ (four patients). AF was detected in only one patient and normal sinus rhythm was achieved after a single dose of intravenous digoxin infusion. ${ }^{12} \mathrm{AF}$ following electrical shock requiring cardioversion with baseline pre-excitation syndrome was reported recently in 2004 by R Akdemir. ${ }^{13}$

According to the American Burn Association's burn center referral criteria, patients with injuries due to electrical burns, including lightning injury, should be referred to a burn center. All patients are evaluated thoroughly irrespective of the level of injury or the voltage of the current. ECG is an integral part. All patients with a history of loss of consciousness, documented arrhythmias either before or after arrival to the emergency department (including cardiac arrest), ECG evidence of ischemia, or who have a sustained a high-voltage electrical injury should be admitted for additional monitoring. ${ }^{14}$ There are no current guidelines regarding duration of anti-arrhythmic drugs after cardioversion in patients of $\mathrm{AF}$ following electrical injury. This patient was therefore managed according to the current guidelines of new-onset $\mathrm{AF}^{15}$

There are reports of delayed cardiac arrest mainly due to ventricular arrhythmias following electrical injury. The possible mechanism being patchy myocardial necrosis causing alteration in the sodium-potassium pump activity of cardiac myocytes. ${ }^{9}$

\section{Conclusion:}

Although uncommon, it is evident that cardiac arrest is a serious and important manifestation following an electrical injury; AF being rarer. Current guidelines regarding basic management including ECG and monitoring of patients presenting to any hospital should be followed.

\section{References:}

1) Solem L, Fischer RP, Strate RG. The natural history of electric injury. J Trauma1977; 17:487-92.

2) Wander GS, Bansal RK, Anand IS, et al. Atrial fibrillation following electrical injury. Jpn Heart J 1992; 33:131-4.

3) Butler ED, Gant TD. Electrical injuries, with special reference to the upper extremities. A review of 182 cases. Am J Surg 1977; 134:95-101.

4) Price TG, Cooper MA. Electrical and lightning injuries. In: Marx JA, Hockberger RS, Walls RM, eds. Rosen's Emergency Medicine Concepts and Clinical Practice. Philadelphia, PA: Mosby-Elsevier; 2006:2267-2278.

5) Arnoldo BD, Purdue GF, Kowalske K, et al. Electrical injuries: a 20-year review. J Burn Care \& Rehabil. 2004; 25(6):479- 
484.

6) Lown B, Neuman J, Amarasingham R, et al Comparison of alternating current with direct electroshock across the closed chest. Am J Cardiol. 1962; 10:223-233.

7) Blackwell N, Hayllar J. A three year prospective audit of 212 presentations to the emergency department after electrical injury with a management protocol. Postgrad Med J. 2002; 78(919); 283-285.

8) Bailey B, Gaudreault P, Thivierge RL. Cardiac monitoring of high-risk patients after an electrical injury: a prospective multicentre study. Emerg Med J. 2007; 24(5):348-352.

9) Jensen PJ, Thomsen PE, Bagger JP, et al. Electrical injury causing ventricular arrhythmias. Br Heart J. 1987; 57(3):279283.)

10) Akdemir R, Gunduz H, Erbilen E, et al Atrial fibrillation after electrical shock: a case report and review. Emerg Med J.
2004; 21(6):744-746.

11) Wander GS, Bansal RK, Anand IS, et al. Atrial fibrillation following electrical injury. Jpn Heart J. 1992; 33(1):131-134.

12) Arrowsmith J, Usgaocar RP, Dickson WA. Electrical injury and the frequency of cardiac complications. Burns 1997; 23:576-8.)

13) R Akdemir, H Gunduz, E Erbilen, I Ozer, et al. Atrial fibrillation after electrical shock: a case report and review. Emerg Med J 2004; 21:744-746.

14) Arnoldo B, Klein M, Gibran NS. Practice guidelines for the management of electrical injuries. J Burn Care Res. 2006; 27(4):439-447.

15) Craig T. January, L. Samuel Wann, et al. 2014 AHA/ACC/ HRS Guideline for the Management of Patients with Atrial Fibrillation: Executive Summary. JACC 2014; 6 4(2 1): 2246 -80 .
Cite this article as: Navaraj Paudel, V.M. Alurkar, R.C Kafle,et al.Atrial fibrillation following electric shock requiring cardioversion.Nepalese Heart Journal 2016;13(1):-31-34. 